\title{
A complex array of Hpr consensus DNA recognition sequences proximal to the enterotoxin gene in Clostridium perfringens type A
}

\author{
Sigrid Brynestad, ${ }^{1}$ Lesley A. Iwanejko, ${ }^{2}$ Gordon S. A. B. Stewart ${ }^{3}$ \\ and Per Einar Granum ${ }^{1}$
}

Author for correspondence: Per Einar Granum. Tel: +4722964845 . Fax: +4722964850 .

\footnotetext{
1 Department of Pharmacology, Microbiology and Food Hygiene, Norwegian College of Veterinary Medicine, PO Box 8146, Dep., N-0033 Oslo, Norway

2 Department of Genetics and Microbiology, University of Liverpool, PO Box 147, Liverpool L69 3BX, UK

3 Department of Applied Biochemistry and Food Science, University of Nottingham, Sutton Bonington Campus, Leicestershire LE12 5RD, UK
}

\begin{abstract}
Enterotoxin production in Clostridium perfringens is both strain dependent and sporulation associated. Underlying these phenotypic observations must lie a genetic and molecular explanation and the principal keys will be held within the DNA sequence both upstream and downstream of the structural gene cpe. In accordance with the above we have sequenced $4.1 \mathrm{kbp}$ of DNA upstream of cpe in the type strain NCTC 8239. A region of DNA extending up to $1.5 \mathrm{~kb} 5^{\prime}$ to cpe is conserved in all enterotoxin-positive strains. This region contains a putative ORF with substantial homology to an ORF in the Salmonella typhimurium IS200 insertion element and, in addition, contains multiple perfect consensus DNA-binding sequences for the Bacillus subtilis transition state regulator Hpr. The detailed structural elements revealed by the sequence analysis are presented and used to develop a new perspective on the molecular basis of enterotoxin production in this important food-poisoning bacterium.
\end{abstract}

Keywords: Clostridium perfringens, enterotoxin, $\mathrm{Hpr}$, IS200, cpe

\section{INTRODUCTION}

Clostridium perfringens type $\mathrm{A}$ is responsible for the classic mild type of food poisoning. Illness is caused by an enterotoxin produced in the small intestine by sporulating bacteria with release of the toxin during mother cell lysis (for reviews, see Granum, 1990; Granum \& Stewart, 1993). Enterotoxin production may vary between strains by as much as three orders of magnitude (Skjelkvåle $e t$ al., 1979; Granum et al., 1984), at least in laboratory media, and inclusion bodies containing the enterotoxin are sometimes observed within the cells (Skjelkvåle \& Duncan, 1975). The use of sporulation mutants has established that enterotoxin is synthesized prior to stage III of sporulation (Duncan et al., 1972), and can be detected immunologically in sporulating cultures after 2-3 h, corresponding to stage II (Duncan, 1973). Stable enterotoxin mRNA with a half-life of some $58 \mathrm{~min}$ has been isolated (Labbe \& Duncan, 1977), but any possible

The EMBL/GenBank/DDBJ accession number for the sequence reported in this paper is $X 71844$. heterogeneity of transcripts has not been investigated. The enterotoxin has been cloned in a number of laboratories (Van Damme-Jongsten et al., 1989; Iwanejko et al., 1989; Hanna et al., 1989), and with the development of a restriction map of the $C$. perfringens genome (Canard et al., 1992) there is now an opportunity to map the cpe gene in relation to other genetic markers on the chromosome.

The ability to produce enterotoxin is not associated with all $C$. perfringens type A strains; indeed only about $6 \%$ of food-isolated strains exhibit this capacity (Van DammeJongsten et al., 1989). It also seems that the ability to produce enterotoxin can come and go within individual culture isolates. Despite past speculation that this relates to changes in gene regulation or even transposition, the underlying genetic basis for these phenotypic observations has not yet been established. As part of the cloning strategy for cpe (Iwanejko et al., 1989) we have previously isolated a substantial region of the DNA $5^{\prime}$ to the structural gene. This DNA should hold many of the keys to the unusual expression phenotype for enterotoxin, as within this region we would expect to find the regulatory elements that specify both an association with sporulation 
and strain variation. In this paper we present the sequence of $4 \cdot 1 \mathrm{kbp}$ of DNA $5^{\prime}$ to cpe. We have compared this region across several strains of $C$. perfringens and we propose a link between an Hpr-like transition state regulator and the sporulation-associated expression of $c p e$.

\section{METHODS}

Strains. All the C. perfringens strains (see Table 3) were from the culture collection of the Norwegian Food Research Institute, As, Norway. The type A strains are all known to be enterotoxin positive (Skjelkvăle et al., 1979), while the type C has been found to be negative (Skjelkvåle \& Duncan, 1975).

Isolation of chromosomal DNA. Chromosomal DNA was extracted from the $C$. perfringens strains using the method of Pitcher et al. (1989). Cells were grown overnight in $100 \mathrm{ml}$ deaired BHI medium (Oxoid) within an anaerobe flask at $37^{\circ} \mathrm{C}$. Cells were harvested by centrifugation $(10000 \mathrm{~g}$ for $15 \mathrm{~min}$ at $4{ }^{\circ} \mathrm{C}$ ). The pellet was resuspended in TE buffer with $500 \mu \mathrm{l}$ lysozyme $\left(50 \mathrm{mg} \mathrm{ml}^{-1}\right)$ and incubated at $37^{\circ} \mathrm{C}$ for $30 \mathrm{~min}$. Then $2.5 \mathrm{ml} \mathrm{GES}$ solution was added (5 M guanidium thiocyanate, $100 \mathrm{mM}$ EDTA, $0.5 \%$ sarcosine). After lysis (rapid) the samples were placed on ice for $10 \mathrm{~min} ; 1.25 \mathrm{ml} 7.5 \mathrm{M}$ ammonium acetate was added, and the samples were again placed on ice for $10 \mathrm{~min}$. The samples were then extracted with $2.5 \mathrm{ml}$ chloroform/ isoamyl alcohol $(24: 1, \mathrm{v} / \mathrm{v})$, mixed and centrifuged $(19000 \mathrm{~g}$ for $15 \mathrm{~min})$. The supernatant was carefully pipetted out and (1.54 vol. cold 2-propanol was added and mixed, and then centrifuged $(4000 \mathrm{~g}$ for about $1 \mathrm{~min}$ ). The pellet was washed with $70 \%$ (v/v) ethanol, dried, and dissolved in $200 \mu \mathrm{l}$ distilled water.

Plasmid isolation. C. perfringens plasmid DNA was isolated either by the use of Magic Miniprep kit (Promega, USA), following the manufacturer's instructions after $1 \mathrm{~h}$ preincubation of the bacterial pellet with $250 \mu \mathrm{g}$ lysozyme (Sigma) plus $10 \mathrm{U}$ mutanolysin (Sigma), or by the following method. Cells were grown in $50 \mathrm{ml} \mathrm{BHI}$ containing $0.4 \%$ glycine within an anaerobe flask until late exponential phase, then centrifuged ( $3000 \mathrm{~g}$ for $15 \mathrm{~min}$ ) and resuspended in $1 \mathrm{ml}$ Tris-sucrose buffer $(50 \mathrm{M}$ Tris $/ \mathrm{HCl} \mathrm{pH} 8.0,5 \mathrm{mM}$ EDTA, $50 \mathrm{mM} \mathrm{NaCl}$ in $25 \%$ sucrose). Lysozyme $\left(0.4 \mathrm{ml}\right.$ of $\left.50 \mathrm{mg} \mathrm{ml}^{-1}\right)$ and mutanolysin $\left(0 \cdot 1 \mathrm{ml}\right.$ of $\left.2000 \mathrm{U} \mathrm{ml}^{-1}\right)$ were added and the samples incubated at $37^{\circ} \mathrm{C}$ for $15 \mathrm{~min}$. EDTA was added up to $60 \mathrm{mM}$, and the samples were incubated at $37^{\circ} \mathrm{C}$ for $10 \mathrm{~min}$. The sample was cooled on ice and $10 \%$ SDS was added to $1 \%$ and left on ice until clear (5-10 min) $\mathrm{NaCl}$ was added to $0.75 \mathrm{M}$, and the samples were left on ice for $20 \mathrm{~min}$, then centrifuged $(19000 \mathrm{~g}$ for $20 \mathrm{~min}$ ). The DNA was precipitated with 2 vols ethanol at $-20^{\circ} \mathrm{C}$ overnight. The pellet was dried under vacuum and dissolved in $200 \mathrm{ml}$ TE.

Plasmids from Escherichia coli were isolated either as described in Sambrook et al. (1989) or using Magic Minipreps (Promega) according to the manufacturer's instructions. All sequenced DNA was prepared using the Magic Miniprep kit.

DNA hybridization. Samples were fractionated on gels, which were dried in a vacuum system (Bio-Rad). The gel was denatured (and deprobed) in $0.5 \mathrm{M} \mathrm{NaOH}, 0.15 \mathrm{M} \mathrm{NaCl}$ for $20 \mathrm{~min}$, and neutralized in $0.5 \mathrm{M}$ Tris $/ \mathrm{HCl} \mathrm{pH} \mathrm{7.5,0.15} \mathrm{M} \mathrm{NaCl}$ for $20 \mathrm{~min}$. The gels were hybridized in a solution containing $6 \times \mathrm{SSC}$ $(1 \times \mathrm{SSC}$ contains $0.15 \mathrm{M} \mathrm{NaCl}$ and $0.015 \mathrm{M}$ sodium citrate), $5 \times$ Denhardt solution $(1 \times$ Denhardt contains $0.02 \%$ Ficoll, $0.02 \%$ polyvinylpyrrolidone, $0.02 \%$ bovine serum albumin fraction $\mathrm{V}$ ) and $0.05 \%$ sodium pyrophosphate in a sealed plastic bag. Probes labelled with ${ }^{32} \mathrm{P}$ were added $(25 \mathrm{ng}$ multiprimelabelled DNA, $200 \mathrm{ng}$ end-labelled) and hybridized for $18 \mathrm{~h}$ at temperatures from $40^{\circ} \mathrm{C}$ to $48^{\circ} \mathrm{C}$ depending on the desired stringency. The gels were given two or three 20 min washes in $6 \times \mathrm{SSC}, 0.05 \%$ sodium pyrophosphate at temperatures in the same range as hybridization. Gels were wrapped in Gladpack and exposed to Amersham hyperfilm with an intensifying screen at $-70^{\circ} \mathrm{C}$. Transformations were performed using competent E. coli strains JM105 or XL-blue as described by Hanahan (1983).

DNA sequencing. Plasmids were sequenced using T7 DNA polymerase and a fluorescent primer (Kristensen et al., 1988). Standard universal and reverse primers for pUC18/19 vectors were used. The products were analysed and the sequence derived using an instrument constructed at EMBL, Heidelberg, Germany (Ansorge et al., 1986, 1987), at the Biotechnology Centre of Oslo, sequencing laboratory.

Polymerase chain reaction. PCR reactions were carried out in a Perkin Elmer Cetus DNA Thermal Cycler using the following programme: 30 cycles at $92{ }^{\circ} \mathrm{C}$ for $1 \mathrm{~min}, 52^{\circ} \mathrm{C}$ for $1 \mathrm{~min}$ and $72{ }^{\circ} \mathrm{C}$ for $1 \mathrm{~min}$. The GeneAmp PCR Core Reagent kit (part no. N808-0009, Perkin Elmer Cetus) was used according to the manufacturer's instructions.

\section{RESULTS}

\section{Sequence analysis of DNA $5^{\prime}$ to the cpe gene}

The cpe clone pLW1 (Iwanejko et al., 1989), which was used in the identification and sequencing of $c p e$, contains a $6.8 \mathrm{~kb}$ DNA insert in plasmid pHG165 (Stewart et al., 1986). cpe and $300 \mathrm{bp} 5^{\prime}$ to the gene were previously sequenced, and regions with homology to a ShineDalgarno consensus sequence and the -35 and -10 promoter sequence for the Clostridium tetani toxin gene identified. This initial sequence strategy did not require detailed restriction analysis of the $6.8 \mathrm{kbp}$ clone and, in consequence, this present study commenced with the development of a more detailed restriction map (Fig. 1), subsequently used for subcloning the DNA into pUC18 plasmids (Yanisch-Perron et al., 1985) for further sequencing. Overlapping clones were obtained over a $2 \mathrm{kbp}$ area and nested deletion clones, using a Pharmacia kit, were made for the remaining areas with no suitable

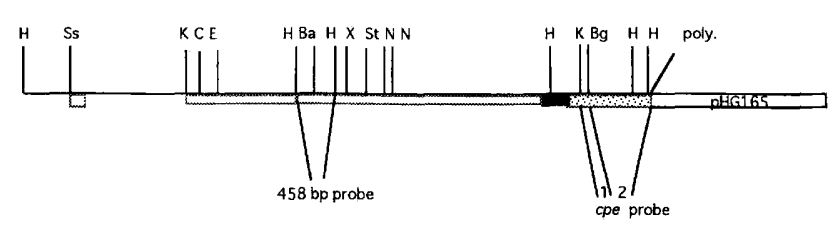

Fig. 1. Restriction map of the cpe clone pLW1 (Iwanejko et al., 1989). The restriction sites are indicated as Bg/ll (Bg), Clal (C), HindIII (H), Kpnl (K), Ncol (N), Sstl (Ss), Stul (St) and Xbal (X). The polylinker of the cloning vector, pHG165, is indicated as poly. Three different probes used are indicated: a $458 \mathrm{bp}$ Hindlll fragment, and a $\mathrm{K}-\mathrm{Bg}$ and a $\mathrm{Bg}-\mathrm{Bg}$ (poly) fragment in the cpe gene. The dotted area indicates the cpe ORF; the shaded area $5^{\prime}$ to cpe has been sequenced before. The open area indicates the new sequence presented in this paper. 

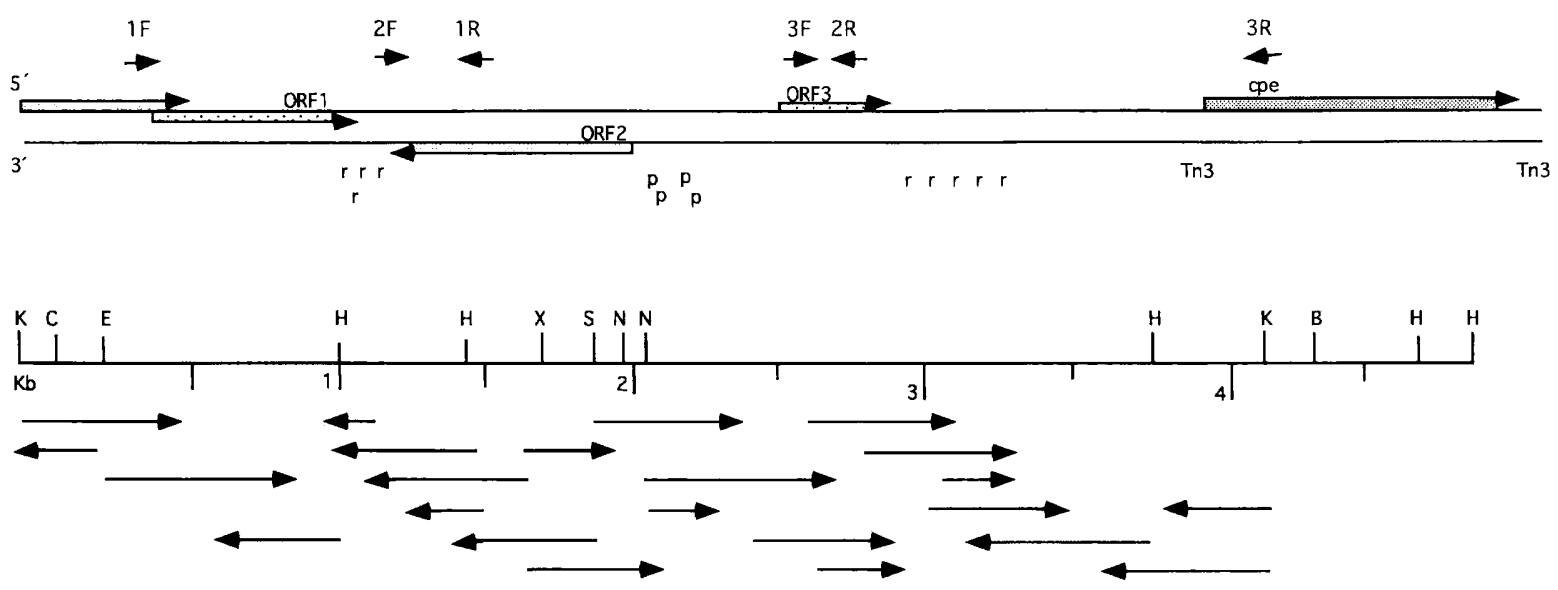

Fig. 2. Map of sequenced DNA from pLW1. Top: indication of open reading frames (ORF), direct repeats ( $r$ ), palindromes (p) and sequences homologous to the recombination sites of Tn3. The position of the primers from Table 3 used in the PCR studies are indicated as arrows on the top of the map. Bottom: arrows indicate the different subclones used for sequencing. The restriction sites are as in Fig. 1.

restriction enzyme sites. Plasmids were subjected to automated sequencing protocols and the final sequence of $5090 \mathrm{bp}$ was constructed with the use of programs from the GCG package (Genetics Computer Group, 1991). The enterotoxin gene and some $3 \mathrm{kbp}$ of proximal DNA has either been sequenced in both directions or has been sequenced several times from separate clones (Fig. 2). The initial $1.7 \mathrm{~kb}$ of the $6.8 \mathrm{kbp}$ clone (the region most distant from $c p e$ ) gave consistently poor sequencing results in the attempts made, and is not included here. The $5090 \mathrm{bp}$ sequenced starts at a $K p n$ I site, and this is considered bp 1 (Fig. 3). Using this convention the cpe gene coding area starts at bp 4131. There is a gap of a few bases after bp 1150 which repeated attempts at sequencing have failed to resolve.

Possible open reading frames (ORFs) were found using the GCG package. In addition to $c p e$, three ORFs were found: ORF1 from bp 369 to 930 (187 amino acids), ORF2 from bp 2134 to 1375 (253 amino acids) and ORF3 from bp 2653 to 2920 ( 89 amino acids). In addition to the above there may be an ORF running into the $5^{\prime}$ end of the sequenced region as bps $0-399$ have an ORF overlapping ORF1. All the sequences and the amino acid translations were compared against known sequences using the FASTA, TFASTA and BLAST programs (Pearson \& Lipman, 1988; Altschul et al., 1990). Only one significant homologous DNA and one protein sequence was found, and only for ORF3 (Fig. 4). This search produced one striking homology at both the DNA and protein level. ORF3, which is the nearest ORF $5^{\prime}$ to cpe, shows $66 \%$ DNA homology and $63 \%$ amino acid homology to a putative ORF in the Salmonella typhimurium insertion sequence IS200 (Fig. 4; Gibert et al., 1991). Ribosome-binding sites (SD) and putative -35 and -10 regions can be located $5^{\prime}$ to all four ORFs (Table 1). Only one plausible SD and -35 and -10 promoter sequences could be detected $5^{\prime}$ to three ORFs upstream of cpe. In contrast, at least ten possible -35 and -10 promoter sequences can be identified upstream of cpe. Nine of these -35 sequences are partly homologous to other known -35 regions from clostridia (Sebald, 1993).

Searches for repeats and palindromes were performed. There was a marked concentration of repeats within 100 bp of each other in the DNA separating the probable ORFs. Between ORF 1 and ORF 2 there are four perfect repeats, five repeats were identified between ORF 3 and cpe, and four palindromes were located between ORF2 and ORF3 (Figs 2 and 3). Sequences resembling the Tn3 recombination site (Sherratt, 1989) were found in multiple copies $5^{\prime}$ to $c p e$, and one copy was found $3^{\prime}$ (Table 2). The two closest to the cpe gene are marked on Fig. 2.

A consensus DNA recognition sequence for the Bacillus subtilis DNA binding protein $\mathrm{Hpr}$ has been deduced from the examination of 10 separate DNase-1-protected regions on four separate genes (Kallio et al., 1991; Strauch \& Hoch, 1993). This sequence is AATANTATT, with the $5^{\prime}$ half being more highly conserved than the $3^{\prime}$ half. Since Hpr has been implicated in the control of many transition state functions in bacilli, a similar system may operate in clostridia. Given the known association with sporulation for cpe expression, regulation by an $\mathrm{Hpr}$ homologue would be consistent with current knowledge. The sequence between ORF3 and cpe contains three pairs of perfect Hpr protein consensus binding sites and, in addition, there is another perfect consensus $3^{\prime}$ to cpe (Fig. 5). This result is important since it is known that both upstream and downstream $\mathrm{Hpr}$ binding sites are required for the full repressive effect of the transition state regulator (Strauch \& Hoch, 1993). Using oligonucleotide primers homologous to $h p r$ (sequences 119-139 forward and 685-704 reverse primer) (Perego \& Hoch, 1988) we isolated from agarose gels, a 586 bp fragment from bpr by PCR. Using the primers for PCR on clostridial DNA was not successful, but Southern hybridization with a ${ }^{32} \mathrm{P}$ - 
1 GCTCGAGTAC CCGTAGTTGC ATTAATAGGA TTAACTTTAC TTCCTGTATC

51 AATCGATTGG GCCGCAGGTG GTGCTGGTTC AGCTAATTAT GCTAGTTTAG

101 AAAATTTAGC TGTGGCTATG TTTGTATTAA TAATAACTCT TTTACTTAA

151 AACTATGGAA AAGGAATGAT AAGTAGTGCT TCAATACTTA TAGGTATAGT

201 TGTAGGATAC ATAGTTTGTA TTCCACTTGG ACTAGTTGAC TTTACTTCTO

251 TAAAGGAGC AAGTTGGCTA TCATTTCCTA AGATCCTTGA ATTCGGAGTA

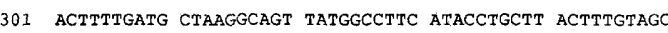

351 CACAATAGGA ACTGTAGGAT GCTTAAAAGC TATTGGAGAG ACATCTTAWT

401 ATIGATATIL_GGTGATAAAA GAGTGGCCGC TGGAGTATTA TCTGATGGTG

451 TAGGAAGTGC ATTAGGTGGA CTAGTAGGTR CTTGTCCTAA TACTTCMTIT

501 AGTCAAAATA TAGGTATTAT TTCTCTAACT AAGGTAGCTA GCCGTCATGT

551 AgctgTAATG GCTGGTATAC IATTAGTTAT CCTIGGCTTC ITACCAAAAG

601 TAGCCGCTAT AATAACAGGA ATACCAAACC CAGTTTTAGG TGGCGTAGGT

651 ATAATGATGT ITGGAACAGT TGCGGCAGCT GGTATIAGBA CACTAAGTAA

701 TATAAAACTI ACAGAGCGTA ATCTTTTAAT AATAGCTATA TCTATGGGGC

751 TTGGACTAGG AGTTACATIT AGACCTGATG TAATTCATAA TCTTCCAGAA

801 GCAATTAGAA TGATCTTCTC ITCTGGAATC TCAACTGGAA CAATAGCTGC

851 CCTAATCCTA AATGCAGTAT TAAAAGAAAG ISCAACATCA ATGGAATITG

901 AaAaratgTa TGATGAAGAA ACAAAGgCTA GTTAAAAAGT TTTAAAGTTA

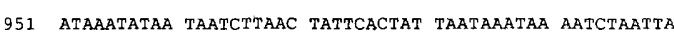

1001 AAAACTAAAT ATATTTTTAT TACATAATAT ACAAATCTAA ATTGCAATAT

1051 CAAATTGAAC TAGTCCTTAA TTATGATTTA AGAACTAATT AATATAATGA

1101 ATATATTTTA TCTAAGTGTA TTTCAAATAA CTCTICTGGA GTCTTGTAAT 1151.

CTCTAGGA AGAGTATTCA TCCAATtTTC TATGAAAGAT ATAGTTTCAA

1201 GTGAGTAATC TGAAATTCGT TTTCCTTTCG GGATAAAACG CCTAATCAGI

1251 CCATTATGAC GCTCATTTGT ACCTTTTTCA AATGAAGAAT ATGGGTGAGT

1301 GAAATACACT TTTAGTTTTF TGTTTTTAGT TCAAATTCTG ATAAATCAGC

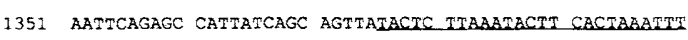

1401 ACTGCCCAAA AATTCITTAA TCRTATCAAG AGCCTTIGTA ACAGATATTG

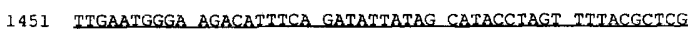

1501 ACAAGTGTIA ACAAAACCTT ATCTITATTA GATTTTRCAC CTAATACACB

1551 GTCTAMTRCC CAATGTCCAA ATTCTTCACG GTTTTCAATA GAATTAGGAC

1601 GATCTGAAAT GCTAGTGCCA AGCTTIITCT TATTATTICT TACTCTAGTA

1651 GACTITITAAT TTCTATGAAG TITAGCTGGT AAATCTATAT TITITATAGG

1701 TAATAAGCCA AGgTCTACAT AGTTATAAAG CGTTITTGTI GAAATAATTI

1751 GAGAAGGACT AAATCTAGAT GAATGCAGAG CITCACCAAC ACATGCATCW

1801 AAAGACCAGT GATCATTCTI ABCTITATCA ACTACATATT TTATAAAATC

1851 ACTACATTCT AATAGTITGT ATTTACGATL AGATTTTAAG CGATTCTTCT

1901 TATAAACAGC TTCACCAGTA TCAGCAAAAT ACACATGAAA ITCCITIACCT

1951 TGCTTAATTT GCTTAGTAGT ACCACGGCGT ATMTCGTITA AAACGGTATT

2001 TATAGGCCTA TrTAGITCTR TIGTATITITA TAAGCTGAAA ATCCATCTTT

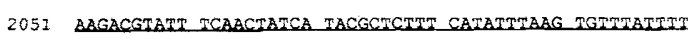

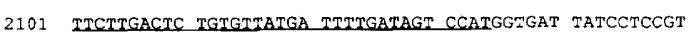

2151 GTGTTTTATT TTTTTACGCG ATtAAATCAT AACACAGGTT AATCCACCAT

2201 GGatTTTTTT ATtTAGTTCA ATPTCATtTT ACAATTAAGC GTATAatAat

2251 TTTAAGCTAT TACTATATGT GAATAGTCTT TCCTTTATTT GAAATTAAGA

2301 AAACAAAGAA AGCTCTATAA AATAAGTAGG GCTTTCTTGT TGTGTAATGA

2351 AaACCACTTG CTATGCGAGT GTGTTCAGAA GAGCTTT'AGC GATtGTAagA

2401 AAAAACCTCC TTTTGTTAAA ATGAAAATAG GTTCGTAGCC AATTTTCGTA

2451 ACAAAAGGAG GGTTTTIAAAT GGATACAAAC AGTTTAGCAC ATACAAAATG

2501 GAatTGTAAa TATCATATAG TTtTTGCACC AaAaCACAGA AGGAaAgaAa
2551 TATATGGAGA GAAAAAACAA GAAATAAGTG AGATATTAAG GCAGCTTTGT

2601 GAATGGAAAG GAGTTAGATA GTCGAAGCGC ACGCTTGCGT AGATCACATA

2651 CACATGCTTG ITGBAATACC ACCTAAAATG AGTGTITCAA GTTTCGTTTG

2701 GGITCTAAAA IGTAAAAETA GTCITATGAT MTMTGAGAAA_ITIGGAAATI

2751 TAAAATATAA ATATGGABAT AGACATTTCT GGTGTATGGG ATTTTACGTI

2801 GATACTGTCG GAAAAAATAA GAAGGCAATT GAAGACTATA TAAGAAATCA

2851 AGAACAAGAA GATATGATAC CTGATCAAAT AAGTITAAAA GAATATATGC

2901 ACACTITTAA GTGTAGCAAG TAAAGAAGTA TGCGGCTGGC GGACTAATTI

2951 AAGCGTCTTA AGATGCAACG TAGGTAGTAT GCCCTTATAG GGCTAAGGAA

3001 ATACCACCAG CTAAGCTGGT GGATTTTTTAT TTtAACTTAG GCACTTATAC

3051 ATAAAGTCTT TTAAATATTT TAACTTAaAT TTCTATAAAT GTTAATTGTG

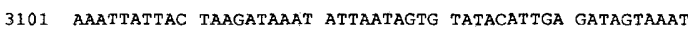

3151 AGCATGATAT TTAAATTTTT AaAgTAaTtT TAaTAAATtT ATATAATTCT

3201 GAAAATATAA AAGGTAGCTC ATTTTAGAGC TACCCTAAAT ACGATTAGAA

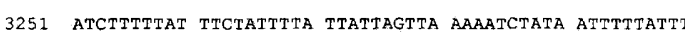

3301 ATACATATTT TCTACTTTTC ACAATAACTG ATGAAATAGA AACTCTAAAT

3351 GaATCAGata CATCACATtA ATGTTCACCA atTCATTTtG TATACAATCT

3401 ATTAACTTGA AGAATGGATT AGTTTATCAA AACTTTAATT AGAGTTATTA

3451 TTATATTTAT TAAAAACTCT CTCCTMTAAA TTAAGTTGAT ATATATGAAA

3501 aATACATACG CAGgGTTAGA GataAaAata GTATTCAAGT TTATAAAATA

3551 CTIAGAGTAT CTATAAACTT GATACTCATT TATTAATAAG ATAAAATTAT

3601 TTATTTTTAT CTTATTAATC GCTATATTCA TTATAGTTAC FTGTTGGGTG

3651 atTTATTACT CCAATAAGTG CCAAAATTTA GAGTATAGCT TTAACTATTT

3701 CTTGATAGTT ATCTGGTAAA ATATTAATTT TAAATCCTTG TAAAACCAAG

3751 GAAATTAAGG TTGCTATAGA AAGCCATAAC CCATAATTCT TAAAACGTGA

3801 trTattTatt ataAtatatc actCrccttG tтtataAtat ataatattat

3851 GTTTAGTGAA ATTATGTTAA TATACTACTT ATtTCTTCTT TTATATTAAT

3901 TAACATTTCA ACTTGATCTC TTTAACGTAT ATCTCTTTTA TTACCCAAGC

3951 tTtaAtTCCT tCAGCATtaA TATCATAaAa tGTCCATGTa GaAatatatt

4001 CAAGATTATT AAAGATATAT ATTATAATTT AATATTTTGT TAATACTTTA

4051 agGatatGTA TCCAAAATAA AAACTTTTAa ATAATATATT ATATAAAAAA

4101 AatTAGAAAT AAGGAGATGT TAATTATAAT ATGCrIAGTA ACAATTITAAa

4151 TCCAATGGTG TICGAAAATG CTAAAGAAGT ATTTCTTATT TCTGAGGATT

4201 TAAAAACACC RATTBATATI ACAAACTCTA ACTCABATIT AAGTGARGGA

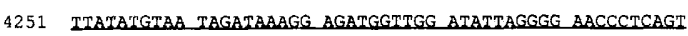

4301 AGTITCAAGT CAAATTCTTA ATCCTAATGA AACAGGTACC TTTAGCCAAT

4351 CATTAACTAA ATCTAAAGAA GTATCTATAA ATGTAAATTI TICAGTIGGA

4401 ITTACTTCTG AATTIATACA AGCATCTGM GAATATGGAT ITGGAATAAC

4451 TATAGGAGAA CAAAATACAA TAGBAAGATC TGTATCTACA ACTGCTGGTC

4501 CAAATGAATA TGTATATTAT AAGGTTIATG CAACTIATAG AAAGTATCAA

4551 GCTATTAGA TTTCTCATGG TAATATCTCT GATGATGGAT CAATTRATAA

4601 ATTAACAGGB ATATGGCTTA GTAAAACATC TGCAGATAGC TMAGGAAATA

4651 TIGATCAAGG TICATTAATT GAAACTGGTG AAAGATGTGT ITTAACAGTT

4701 CCATCTACAG ATATAGAAAA GGAAATCCTI GATTRAGCTG CTGCTACAGA

4751 AAGATTAAAT TTAACTGATG CATTAAACTC AAACCCAGCT GGAAATTTAT

4801 ATGATTGGCG TTCTYCTAAC ICATACCCT: GGACTCAAAA GCTTAATTTA

4851 CACTTAACAA TIACAGCTAC IGGACAAAAA TATAGAATCT TAGCTAGCAB

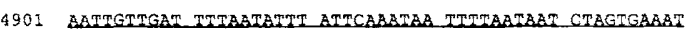

4951 TAGAACAGTC CTIAGgTGAT GGAGTAAAAG ATCATTATGT TGATATAaGC

5001 TTAGATGCCG GACAATATGT TCTTGTAATG AAAGCTAATT CATCATATAG

5051 TGGAAACTCT CACCCTTATT CAATATTATT TCAAAAATTT

Fig. 3. For legend see opposite page. 
labelled 586 bp B. subtilis DNA fragment gave a positive hybridization band for all the $C$. perfringens strains (Table 3). We are currently seeking a gene with homology to $h p r$ from C. perfringens.

\section{Hybridization studies on DNA from various $C$. perfringens strains}

Chromosomal DNA was isolated from nine $C$. perfringens strains (Table 3) which were tested for toxin production with a latex agglutination test kit (Oxoid). A $240 \mathrm{bp}$ $K p n \mathrm{I}-B g l \mathrm{II}$ probe for the $c p e$ gene, and a 458 bp HindIII fragment upstream from cpe (Fig. 1) were labelled with ${ }^{32} \mathrm{P}$ and used in Southern hybridization with EcoRI-digested chromosomal DNA separated on a $0.7 \%$ agarose gel. The cpe probe gave a single signal in the enterotoxin-positive strains, and no signal in enterotoxin-negative strains (Table 3). Despite the above, the hybridization band position was different for each strain, suggesting significant heterogeneity in chromosomal location.

The $458 \mathrm{bp}$ HindIII fragment (determined to be 330 bp on agarose gel: Granum \& Stewart, 1993) gave a very different picture, with hybridization band numbers varying from one to three to multiple. These results extended the previous studies with $C$. perfringens NCTC 8239 (Granum \& Stewart, 1993), where multiple repeats of this region were first identified. Two of the enterotoxin-negative strains gave positive hybridization with this probe, including a type D strain; of particular interest, however, was that one of the enterotoxin-positive strains gave no hybridization signal, indicating that this region can be uncoupled from enterotoxin expression.

\section{PCR studies of DNA upstream of cpe}

The analysis using the two probes described above indicated that a region $2.5 \mathrm{kpb}$ upstream of cpe may be unlinked to the regulation of enterotoxin production. However, the potential importance of ORF3 and the $\mathrm{Hpr}$ consensus binding sequences remain unclear and an extension of the above study to incorporate these areas in a linking study should prove helpful. A PCR approach was used to indicate the presence in diverse $C$. perfringens strains of the sequences up to $4 \mathrm{kbp} 5^{\prime}$ to cpe in $C$. perfringens NCTC 8239. PCR primers were constructed according to Table 4 and Fig. 2 and these provided amplification of three separate but partly overlapping regions proximal to $c p e$. Of the six enterotoxin-positive strains tested only two in addition to NCTC 8239 gave PCR fragments of the expected size, indicating an equivalent genetic structure (Table 3). The PCR1 1213 bp fragment and the PCR2 1697 fragment were either absent or truncated in all of the remaining strains, indicating, as above, that these regions are unlinked to cpe expression. Of particular significance, however, was the finding that the PCR3 $1397 \mathrm{bp}$ fragment, which includes most of ORF3 and all of the intervening region up to cpe, was present in the correct size in all enterotoxin-positive strains.

\section{DISCUSSION}

About $4.1 \mathrm{~kb}$ DNA upstream of the enterotoxin gene from $C$. perfringens NCTC 8239 has been sequenced and subjected to detailed analysis. We have identified three ORFs, with possible associated control sequences, upstream of cpe (Fig. 2). ORF1 and ORF3 are found on the same coding strand as cpe, while ORF2 is on the other strand. Of the region associated with cpe in strain NCTC 8239 only that from the start of ORF3 to cpe is conserved among enterotoxin-positive $C$. perfringens strains. It is reasonable to assume therefore that ORFs 1 and 2 and their associated intergenic sequences are not an integral part of the control of $c p e$ expression. Nevertheless the potential involvement of these regions in mediating the overall level of cpe expression cannot be excluded. Given that ORF3 does appear linked to cpe in all strains it is particularly interesting that it has such high homology with the C-terminal end of a putative ORF from $S$. typhimurium insertion sequence IS 200 (Fig. 4). It is possible that the IS 200 sequence actually produces this peptide as homology starts with ORF3 methionine and shows $93 \%$ conservation over the first 14 amino acids. At present the functional significance of this is unknown, but two additional observations support the association of the ORF3 region with mobilizable elements. Firstly the DNA sequence which includes ORF 3 is completely devoid of 6 base restriction endonuclease palindromes. Such an absence is strongly suggestive of selection pressure derived from interspecies DNA transfer which might occur on mobilizable plasmids or bacteriophages. The absence of 6 base palindromes in $\mathrm{T} 7$ for example has been ascribed to elimination by phage replication in multiple hosts having diverse type II endonucleases (Rosenberg et al., 1979). In this regard it is also interesting to note that $C$. perfringens enterotoxin, like the Stapbylococcus aureus enterotoxins, is a superantigen (Bowness et al., 1992). The term superantigen has been applied to a group of bacterial and retroviral proteins that stimulate a large number of $T$ lymphocytes in a manner distinct from that of classic antigens. Since at least some, if not all, of the Staph. aureus enterotoxins are known to be phage mediated (Alouf et al., 1991) it is quite possible that the superantigenic enterotoxins are of viral (phage) origin. Returning to the second factor indicating the potential for cpe mobilization, there are sequences resembling the $\operatorname{Tn} 3$ recombination site both upstream and downstream of cpe (Table 2). It

Fig. 3. The sequence of 5090 bases from the Knpl site (Fig. 1) $5^{\prime}$ to cpe. The sequence of the Knpl-Knpl fragment (Fig. 2) is from this study, while the sequence of the remaining part of cpe and 99 bases $3^{\prime}$ of the gene is from Iwanejko et al. (1989) and Van Damme-Jongsten et al. (1989). The four ORFs are underlined. 


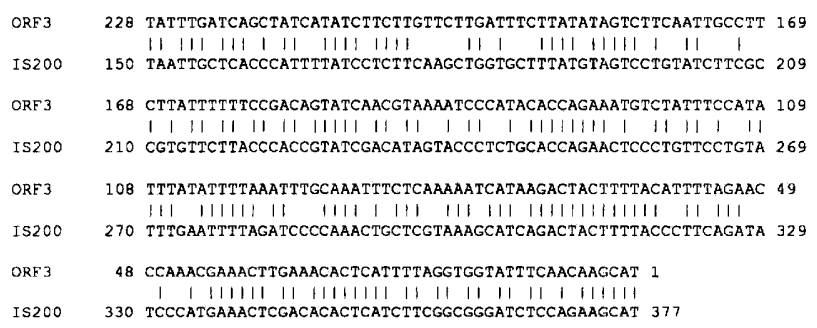

ORF 3

IS200

ORF 3

I5200

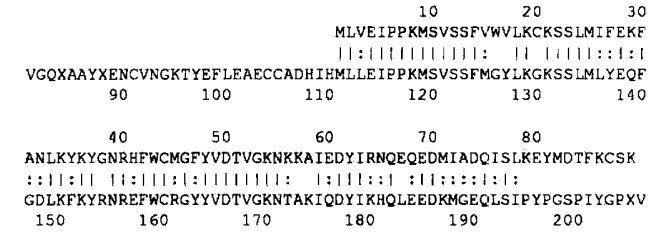

Fig. 4. Sequence homologies between the DNA and translated amino acids of ORF3 and the IS200 from S. typhimurium (Gibert et al., 1991).

Table 1. Putative ribosome-binding sites (SD) and promoter sequences found 5 to the ORFs in Fig. 3

The relative positions of the sequences to the start codon of the ORFs are shown.

\begin{tabular}{|c|c|c|c|}
\hline & \multirow[t]{2}{*}{ SD sequence } & \multicolumn{2}{|c|}{ Promoter sequences } \\
\hline & & $\begin{array}{c}-35 \\
\text { region }\end{array}$ & $\begin{array}{c}-10 \\
\text { region }\end{array}$ \\
\hline \multirow{3}{*}{ ORF 1} & -5 & -195 & -170 \\
\hline & AGGAACTG & AATGATAAG & TATA \\
\hline & -50 & -132 & -107 \\
\hline \multirow[t]{2}{*}{ ORF 2} & T'TAACCTG & TATTCACATT & TTATA \\
\hline & -37 & -159 & -134 \\
\hline \multirow[t]{2}{*}{ ORF 3} & AGGAGTTA & GTTTAGCACATAC & TATA \\
\hline & -11 & -28 & -3 \\
\hline \multirow[t]{19}{*}{ CPE } & AGGAGATG & ATATAAAAAAAAT & TTATA \\
\hline & & -60 & -35 \\
\hline & & TCCAAAATAA & TATA \\
\hline & & -157 & -132 \\
\hline & & TTCAGCATTAATAT & TATA \\
\hline & & -260 & -235 \\
\hline & & AAATTATGTTAA & TTATA \\
\hline & & -281 & -256 \\
\hline & & ATATAATATTA & TATA \\
\hline & & -520 & -495 \\
\hline & & ATTTATTTTTA'T & TTATA \\
\hline & & -590 & -565 \\
\hline & & ATAGTATTCAAGT & TATA \\
\hline & & -946 & -921 \\
\hline & & TAATTTTAAT & TATA \\
\hline & & -961 & -936 \\
\hline & & ATATT'TAAATT'T & TATA \\
\hline & & -1021 & -996 \\
\hline & & TGAAATTATTA & TATA \\
\hline
\end{tabular}

Table 2. Tn3 recombination site consensus comparison

\begin{tabular}{|c|c|c|}
\hline & & $\begin{array}{c}\text { Position } \\
\text { relative } \\
\text { to cpe }\end{array}$ \\
\hline $5^{\prime}$ & $\begin{array}{l}\text { AATATTTTAACTT } \\
\text { TATTATTAGTTA } \\
\text { AGTTATTATTATA } \\
\text { AAATTATTTA } \\
\text { AAATATTAATTTT } \\
\text { AATATATAATATTAT } \\
\text { AAGATTATTAA } \\
\text { AAATAATATATTATATA }\end{array}$ & $\begin{array}{r}-1055 \\
-850 \\
-576 \\
-528 \\
-399 \\
-280 \\
-118 \\
-36\end{array}$ \\
\hline $3^{\prime}$ & AATATTATTTCAAAAA & +80 \\
\hline $\operatorname{Tn} 3 *$ & AAATATTATAAATTAT & \\
\hline
\end{tabular}

* Sherratt (1989).

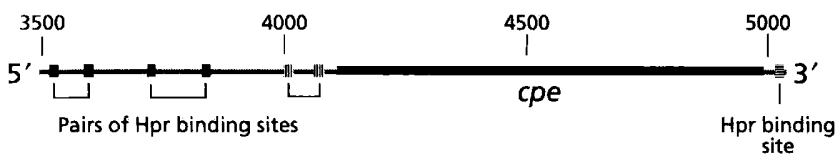

Fig. 5. The positions of the $\mathrm{Hpr}$ binding sequences up- and downstream of the cpe (the numbering of the bases at the top is as in Fig. 3). The sequences of three pairs of $\mathrm{Hpr}$ binding sites upstream to cpe are: AATAGTATT, AAAATTATT; AATATTAAT, AATATTATG; AAGATTATT, AATAATATA (starting point of each of the sequences: $3527,3593,3720,3843,4002$ and 4080). A single $\mathrm{Hpr}$ binding sequence is observed downstream of cpe: AATATTATT (starting point 5072).

certainly appears that excision of $c$ e and the DNA region including ORF 3 is possible since $C$. perfringens 2154 which has previously been described as enterotoxin positive (Skjelkvåle et al., 1979) now appears deleted in this region (Table 3).

It has long been known that some strains of $C$. perfringens produce enormous amounts of enterotoxin, and the possibility of multiple copies of cpe scattered around the genome has been a plausible explanation. This theory can however be ruled out, as only a single cpe gene is found in such strains, located at the position close to the origin of genome replication (Canard et al., 1992). Since mRNA stability appears to be excluded (Labbe \& Duncan, 1977), a possible explanation could be that differential use of at least some of the 10 putative RNA polymerase binding sequences upstream of cpe allows for different levels of transcription and/or coupled translation. This aspect is currently being examined by isolation of mRNA during sporulation of $C$. perfringens and transcript mapping.

For the first time since the early observation of Duncan $e t$ al. (1972) a clear molecular link between enterotoxin production and sporulation has been discovered. An Hpr- 
Table 3. C. perfringens strains used for hybridization and PCR studies

\begin{tabular}{|c|c|c|c|c|c|c|c|}
\hline & \multirow[t]{2}{*}{ Type } & \multicolumn{3}{|c|}{ Probes* } & \multicolumn{3}{|c|}{ PCR primers used* } \\
\hline & & $\mathbf{H p r}$ & $c p e$ & HindIII & $\begin{array}{c}\text { PCR1 } \\
1213 \text { bp }\end{array}$ & $\begin{array}{c}\text { PCR2 } \\
1697 \mathrm{bp}\end{array}$ & $\begin{array}{c}\text { PCR3 } \\
1397 \text { bp }\end{array}$ \\
\hline NCTC 8239 & A & + & + & multiple & + & + & + \\
\hline 1090 & A & + & + & 3 & + & $+(\mathrm{S} 1)$ & + \\
\hline 1995 & A & + & + & - & - & - & + \\
\hline $2154 t$ & A & + & - & ND & $+(\mathrm{S} 2)$ & - & - \\
\hline 2672 & A & + & + & multiple & + & + & + \\
\hline 4457 & A & + & + & - & - & - & + \\
\hline 4743 & A & + & + & 1 & + & + & + \\
\hline 5387 & $\mathrm{C}$ & + & - & 3 & $+(\mathrm{S} 2)$ & - & - \\
\hline FD & $\mathrm{D}$ & + & - & - & - & - & - \\
\hline
\end{tabular}

$*+$, positive result; - , negative result; $+(\mathrm{S} 1)$, positive result, about $800 \mathrm{bp}$ smaller than expected; $+(\mathrm{S} 2)$, positive result, about $400 \mathrm{bp}$ smaller than expected; ND, not determined.

$\uparrow$ Has been enterotoxin positive (Skjelkvåle et al., 1979).

Table 4. Primers and probes used in the study of the architecture of the DNA $5^{\prime}$ of the cpe on different strains of $C$. perfringens

\begin{tabular}{|lcl|}
\hline $\begin{array}{l}\text { Primer } \\
\text { names* }\end{array}$ & $\begin{array}{c}\text { Position of } \\
\text { sequences }\end{array}$ & \multicolumn{1}{c|}{ Primer sequences } \\
\hline PCR1 F & $377-397$ & AAGCTATTGGAGAGACATCT \\
PCR1 R & $1590-1569$ & TGAAAACCGTGAAGAATTTGG \\
PCR2 F & $1221-1241$ & TCCTTTCGGGATAAAACGC \\
PCR2 R & $2918-2898$ & TGCTACACTTAAAAGTGTCC \\
PCR3 F & $2773-2793$ & ACATTTCTGGTGTATGGGAT \\
PCR3 R & $4170-4151$ & CATTTTCGAACACATTGGA \\
\hline
\end{tabular}

$* \mathrm{R}$, reverse; $\mathrm{F}$, forward.

like transition state regulator seems to be present in $C$. perfringens and fully conserved $\mathrm{Hpr}$ consensus binding sequences appear both $5^{\prime}$ and $3^{\prime}$ to $c p e$. It might be argued that such sequences may appear at random in DNA with high AT content. However, we have searched among the 34 different $C$. perfringens genes present in the EMBL database, and have not come across a single gene with an Hpr-binding sequence in pairs, or both up- and downstream of a gene. The DNA region containing the $5^{\prime}$ sequence is fully conserved in terms of PCR fragment size between all enterotoxin-positive strains tested. Thus, a mechanism of Hpr-linked repression of cpe expression until entry into the transition state would seem to be indicated. Even in B. subtilis, however, where lowering of bpr expression is observed upon entry into the transition state, the mechanism of control is only partly understood (Strauch \& Hoch, 1993). It will be especially interesting to develop these studies in parallel for sporulation within the anaerobic clostridia.

\section{REFERENCES}

Alouf, J. E., Knöll, H. \& Köhler, W. (1991). The family of mitogenic, shock-inducing and superantigenic toxins from staphylococci and streptococci. In Sourcebook of Bacterial Protein Toxins, pp. 367-414. Edited by J. E. Alouf \& J. H. Freer. London: Academic Press.

Altschul, S., Gish, W., Miller, W., Myers, E. \& Lipman, D. (1990). A basic logical alignment search tool. J Mol Biol 215, 403-410.

Ansorge, W., Sproat, B. S., Stegeman, J. \& Schwager, D. (1986). A non radioactive automated method for DNA sequence determination. J Biochem Biophys Methods 13, 315-323.

Ansorge, W., Sproat, B. S., Stegeman, J., Schwager, D. \& Zenke, M. (1987). Automated DNA sequencing: ultrasensitive detection of fluorescent bands during electrophoresis. Nucleic Acids Res 15, 4593-4602.

Bowness, P., Moss, P. A., Tranter, H., Bell, J. I. \& McMichael, A. J. (1992). Clostridium perfringens enterotoxin is a superantigen reactive with human $\mathrm{T}$ cell receptor $\mathrm{Vb} 6.9$ and $\mathrm{Vb} 22 . J$ Exp Med 176, 893-896.

Canard, B., Saint-Joanis, B. \& Cole, S. T. (1992). Genomic diversity and organization of virulence genes in the pathogenic anaerobe Clostridium perfringens. Mol Microbiol 6, 142-1429.

Duncan, C. L., Strong, D. H. \& Sebald, M. (1972). Sporulation and enterotoxin production by mutants of Clostridium perfringens. $J$ Bacteriol 110, 378-391.

Gibert, I., Carroll, K., Hillyard, D. R., Barbé, J. \& Casadesus, J. (1991). IS200 is not a member of the IS 600 family of insertion sequences. Nucleic Acids Res 19, 1343.

Granum, P. E. (1990). Clostridium perfringens toxins involved in food poisoning. Int J Food Microbiol 10, 101-112.

Granum, P. E. \& Stewart, G. S. A. B. (1993). Molecular biology of Clostridium perfringens enterotoxin. In Genetics and Molecular Biology of Anaerabic Bacteria, pp. 235-247. Edited by M. Sebald. New York: Springer.

Granum, P. E., Telle, W., Olsvik, O. \& Stavn, A. (1984). Enterotoxin formation by Clostridium perfringens during sporulation and vegetative growth. Int J Food Microbiol 1, 43-49. 
Hanahan, D. (1983). Studies on transformation of Eschericbia coli with plasmids. J Mol Biol 166, 557-580.

Hanna, P. C., Wnek, A. P. \& McClane, B. A. (1989). Molecular cloning of the $3^{\prime}$ half of the Clostridium perfringens enterotoxin gene and demonstration that this region encodes receptor-binding activity. J Bacteriol 171, 6815-6820.

Iwanejko, L. A., Routledge, M. N. \& Stewart, G. S. A. B. (1989). Cloning in Escbericbia coli of the enterotoxin gene from Clostridium perfringens type A. J Gen Microbiol 135, 903-909.

Kallio, P. T., Fagelson, J. E., Hoch, J. A. \& Strauch, M. A. (1991). The transition state regulator $\mathrm{Hpr}$ of Bacillus subtilis is a DNAbinding protein. J Biol Chem 266, 13411-13417.

Kristensen, T., Voss, H., Schwager, J., Stegemann, J., Sproat, B. \& Ansorge, W. (1988). T7 DNA polymerase in automated dideoxy sequencing. Nucleic Acids Res 16, 3487-3496.

Labbe, R. G. \& Duncan, C. L. (1977). Evidence for stable messenger ribonucleic acid during sporulation and enterotoxin synthesis by Clostridium perfringens type A. J Bacteriol 129, 843-849.

Pearson, W. \& Lipman, D. (1988). Improved tools for biological sequence comparison. Proc Natl Acad Sci US A 85, 2444-2448.

Perego, M. \& Hoch, J. A. (1988). Sequence analysis and regulation of the $b p r$ locus, a regulatory gene for protease production and sporulation in Bacillus subtilis. J Bacteriol 170, 2560-2567.

Pitcher, D. D., Saunders, N. A. \& Owen, R. J. (1989). Rapid extraction of bacterial genomic DNA with guanidium thiocyanate. Lett Appl Microbiol 8, 151-156.

Rosenberg, A. H., Simon, M. N., Studier, W. F. \& Roberts, R. J. (1979). Survey and mapping of endonuclease cleavage sites in bacteriophage T7 DNA. J Mol Biol 135, 907-915.

Sambrook, J., Fritsch, E. F. \& Maniatis, T. (1989). Molecular Cloning : a Laboratory Manual, 2nd edn. Cold Spring Harbor, NY: Cold Spring Harbor Laboratory.

Sebald, M. (1993). Genetics and Molecular Biology of Anaerobic Bacteria. New York: Springer.

Sherratt, D. (1989). Tn 3 and related transposable elements: site specific recombination and transposition. In Mobile $D N A$, pp. 163-184. Edited by D. E. Berg \& M. M. Howe. Washington, DC: American Society for Microbiology.

Skjelkvåle, R. \& Duncan, C. L. (1975). Enterotoxin formation by different toxigenic types of Clostridium perfringens. Infect Immun 11, 563-575.

Skjelkvåle, R., Stringer, M. F. \& Smart, J. L. (1979). Enterotoxin production by lecithinase-positive and lecithinase-negative Clostridium perfringens isolated from food poisoning outbreaks and other sources. J Appl Microbiol 47, 329-339.

Strauch, M. A. \& Hoch, J. A. (1993). Transition-state regulators: sentinels of Bacillus subtilis post-exponential gene expression. Mol Microbiol 7, 337-342.

Stewart, G. S. A. B., Lubinsky-Mink, S., Jackson, C. G., Cassel, A. \& Kuhn, J. (1986). pHG165: a pBR322 copy number derivative of pUC8 for cloning and expression. Plasmid 15, 172-181.

Van Damme-Jongsten, M., Wernars, K. \& Notermans, S. (1989). Cloning and sequencing of the Clostridium perfringens enterotoxin gene. Antonie Leewwenboek 56, 181-190.

Yanisch-Perron, C., Vieira, J. \& Messing, J. (1985). Improved M13 phage cloning vectors and host strains: nucleotide sequence of the M13mp18 and pUC19 vectors. Gene 33, 103-119.

Received 23 June 1993; revised 13 September 1993; accepted 15 September 1993. 